\title{
Trends in water requirements of wheat crop under projected climates in India
}

\author{
V.P. PRAMOD, B. BAPUJI RAO, S.S.V.S. RAMAKRISHNA ${ }^{1}$, V.M. SANDEEP, N. R. PATEL ${ }^{2}$, M.A. \\ SARATH CHANDRAN, V.U.M. RAO, P. SANTHIBHUSHAN CHOWDARY and P. VIJAYA KUMAR
}

\author{
Central Research Institute for Dryland Agriculture, Santoshnagar, Hyderabad - 500059 \\ ${ }^{1}$ Department of Meteorology and Oceanography, Andhra University, Visakhapatnam - 530004 \\ ${ }^{2}$ Indian Institute of Remote Sensing, Dehradun- 248001 \\ Email:pramodvp1@gmail.com
}

\begin{abstract}
Various global circulation models predict a change in net irrigation requirements worldwide due to the impacts of climate change and in India, depending upon the region, irrigation requirements are likely to change by different magnitudes. The spatial distribution of trend in crop and irrigation water requirements of wheat projected for two climatic periods (2021-50 and 2051-80) across major wheat growing districts of the country were analyzed, making use of climate change projection data from NorESM1-M model of the CMIP5 in combination with RCP 4.5. Decreasing trends in water requirements were projected over 90 per cent of wheat growing districts in 2021-50, whereas increasing trends in crop and irrigation water requirement are expected over 95.4 per cent and 62.4 per cent areas, respectively in 2051-80 climatic periods. Results showed that decreasing/increasing trends projected in water requirements of wheat crop is due to change in crop growing period, which is projected to decrease across entire wheat growing area in 2021-50, whereas it is likely to increase over 78.2 per cent in 205180 climatic periods.
\end{abstract}

Key words: Water requirement, irrigation requirement, crop growing period, climate change, trends, future scenarios

The impacts of climate change accelerate the hydrological cycle resulting in changes in precipitation, evapotranspiration, run-off, and in the intensity and frequency of floods and droughts, which eventually affect crop growth and development (IPCC, 1995). The agricultural irrigation demand in arid and semi-arid regions of Asia is found to increase by at least by 10 per cent for an increase in temperature of $1^{\circ} \mathrm{C}$ ( Liu, 2002). In India, wheat forms the second important staple food crop after rice, whose projected demand by the year 2025 will be high for an estimated population of 1.25 billion and the country has to produce 105 million tons by 2025 . This challenge will probably be further compounded by reduced water availability (Shiklomanov and Rodda, 2003), due to the impacts of climate change. In the wake of changing climate, estimating the water requirement in wheat under projected climate change scenarios can improve our preparedness to meet the irrigation demand in future and ensure food security.

The future crop water requirement (CWR) and irrigation water requirement (IWR) of major crops like groundnut, soybean, wheat, and rabi sorghum from different parts of the country estimated by Bapuji Rao et al. (2012). Rabi sorghum and wheat require additional irrigation requirement of different magnitudes to sustain the current production levels. Parekh and Prajapati (2013), in their study on wheat CWR concluded that negligible decrease in CWR during 2011-2020, whereas a likely increase in CWR during future climate slices viz., 2021-2030, 2046-2065 and 2080-2099. Compared to other research findings, Chattaraj et al. (2014) by conducting a field experiment in a semi arid region of the Indo-Gangetic Plains (IGP) of India reported that CWR of wheat are likely to be less in 2020-21 and 2050-51. They concluded that the projected decrease in water requirement may be either through shortening of growing period or decline in solar radiation. Although a number of studies have previously been conducted in India to estimate future water requirement of wheat, these were limited either to a district or to a maximum of four or five districts of a state/region. In this study, we investigate spatial and temporal variations of water requirements of wheat in major crop growing districts of the country utilizing the historical weather data and projected climatic change scenario using NorESM1-M general circulation model $(\mathrm{GCM})$, which is developed as part of the CMIP5, in combination with RCP 4.5 . 


\section{MATERIALS AND METHODS}

\section{Weather and crop data}

The major wheat growing districts (227) from 11 states (Uttar Pradesh, Madhya Pradesh, Punjab, Haryana, Rajasthan, Bihar, Maharashtra, Gujarat, West Bengal, Chhattisgarh and Jharkhand), that contributes 96 per cent area of wheat grown in the country is considered in the present study. For climatic analysis, we have considered three scenarios, baseline (1981-2010) and two future climatic periods (2021-2050 and 2051-2080). Daily data on maximum temperature $\left(\mathrm{T}_{\max }\right)$, minimum temperatures $\left(\mathrm{T}_{\text {min }}\right)$ at $1^{\circ} \times 1^{\circ}$ and rainfall at $0.25^{\circ} \times 0.25^{\circ}$ resolution were sourced from India Meteorological Department (IMD) for baseline scenario. Weather data $\left(\mathrm{T}_{\max }, \mathrm{T}_{\min }\right.$ and rainfall @ $0.25^{\circ}$ resolution) for future climatic periods was downloaded from NorESM1-M, developed as part of the Coupled Model Intercomparison Project 5 (CMIP5), in combination with Representative Concentration Pathway (RCP) 4.5. NorESM1-M was selected as they represent Indian monsoon as well as air temperature among other CMIP5 models in a better way (Garg et al., 2015; Sandeep et al., 2017).

Across the study regions, wheat season starts from $1^{\text {st }}$ to $2^{\text {nd }}$ fortnight (normal sown) of November to $1^{\text {st }}$ to $2^{\text {nd }}$ fortnight (late sown) of December. Growing season ends by March $2^{\text {nd }}$ fortnight (normal sown) to April $1^{\text {st }}$ fortnight (late sown). For our analysis domain, we considered November to March as normal growing season (sowing to maturity). The spatial average daily temperature $\left(\mathrm{T}_{\max }\right.$ and $\left.\mathrm{T}_{\text {min }}\right)$ and rainfall for each wheat growing district for baseline and two future climatic period was computed considering the number of grids falling in that district. Influential area of a grid was computed using the Thiessen polygon method in a GIS environment (ESRI-ArcGIS 10.0).

\section{Computation of crop and irrigation water requirements}

Using the reference crop evapotranspiration $\left(\mathrm{ET}_{0}\right)$, crop coefficient $\left(\mathrm{K}_{\mathrm{c}}\right)$ and effective rainfall, the CWR and IWR of 227 districts were determined for baseline as well as for two future climatic periods (2021-50 and 2051-80). The methodology used by Sandeep et al. (2017) in computing the water requirements is employed in the present study. Mann Kendall trend test was used in detecting the trends in water requirements of wheat for the future climatic periods.

\section{Estimation of crop duration}

The crop duration of wheat crop for each year in future climatic period has been estimated from growing degree days (GDD), or heat unit, given by the relation

$$
\mathrm{GDD}=\left\lfloor\frac{\mathrm{T}_{\max }+\mathrm{T}_{\min }}{2}\right\rfloor-\mathrm{T}_{\text {base }}
$$

where $T_{\text {base }}$ is the base temperature of the crop. For wheat, $\mathrm{T}_{\text {base }}$ of $5{ }^{\circ} \mathrm{C}$ was considered (Nuttonson, 1955). Irrespective of dates of sowing, heat unit accumulation of crop has remained almost similar at all stage, with decrease in crop duration in response to delay sowing (Pgryan Kumari et al., 2009). Late sowing decreased the duration of phenology, particularly between flowering and maturity, as compared to normal sowing due to unfavourable high temperature during the growing period. Since there is no observed data on crop phenology, average accumulated GDD was calculated for each district during normal crop growing season with respect to baseline data. Hence, the number of days took in achieving the average AGDD for each year in future climatic period was considered as the growing period of a particular district.

\section{RESULTS AND DISCUSSION}

\section{Spatial distribution of water requirements during baseline scenario}

The spatial distribution of average water requirements (CWR and IWR) across 227 districts during the baseline scenario (1981-2010) is shown in Fig. 1. CWR shows a gradient with minimum requirement occurring particularly over north and northwestern regions, with increasing influence southwards (Fig. 1a). The relatively lowest water requirements $(<350 \mathrm{~mm})$ were found in Punjab, Haryana, Uttar Pradesh and Bihar states, because these states combine a cold winter and relatively a long cool growing season. On the other hand, the highest water requirements $(>550 \mathrm{~mm})$ for wheat were found in the districts of Maharashtra. The spatial distribution of IWR is a mirror image of CWR during the baseline (Fig. 1b). Like CWR, minimum requirement of irrigation occurs over north and northwestern regions, with increasing influence southwards. If the temperature is attributed to lower CWR in north and northwestern regions, the rainfall activity due to western disturbance during the crop season was the reason for less IWR across these regions.

\section{Projected trends in water requirements}

Trend analysis of water requirements of wheat crop projected for two future climatic periods are discussed separately. Numbers of districts per state that show a trend, and average slope of the trend, determined using Sen's method, are presented in a tabular form. 

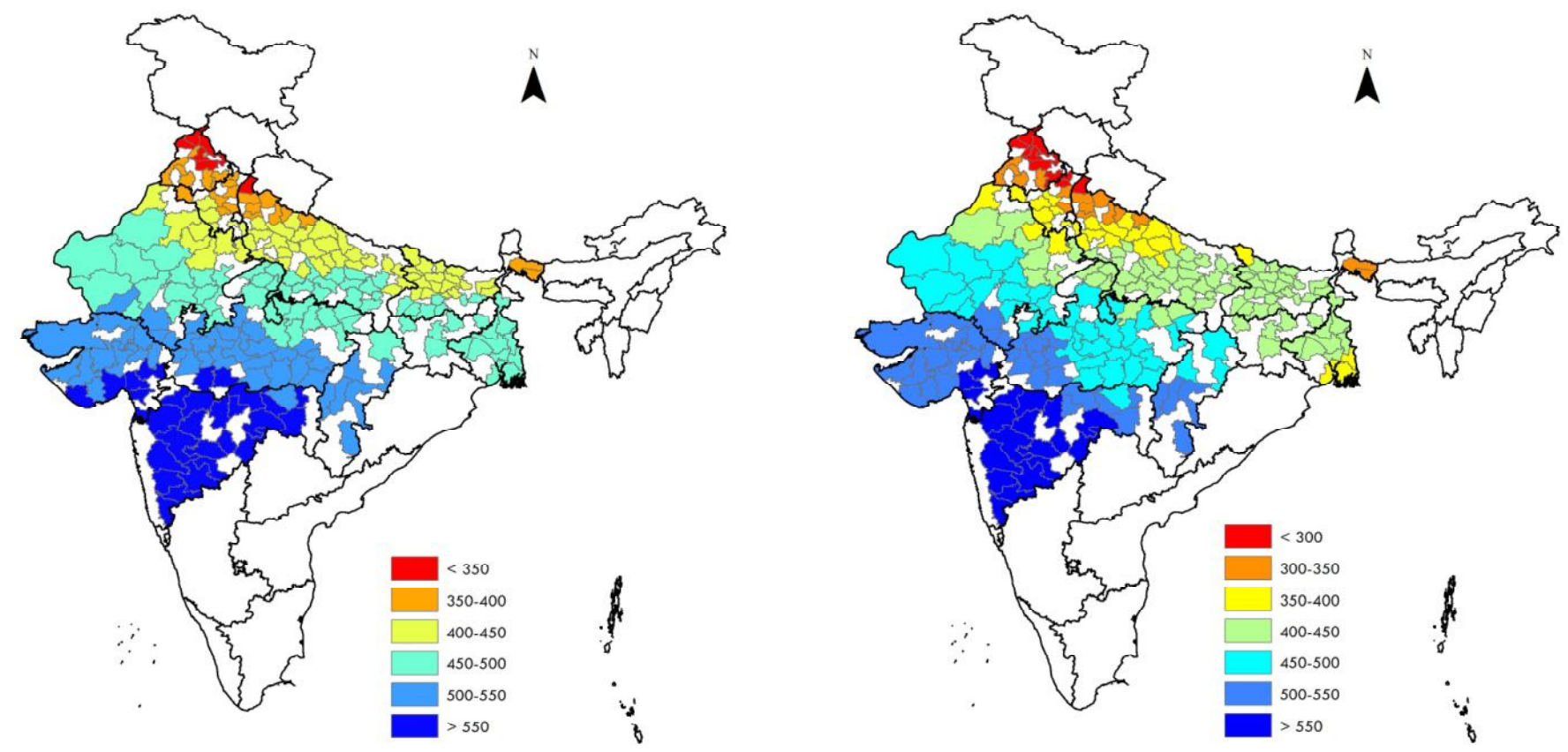

Fig. 1: Spatial distribution of average (a) CWR and (b) IWR (mm) during the baseline scenario

During climatic period 2021-50 the result shows that the Mann-Kendall test projects a decreasing trend in CWR in districts, and there was a significant trend in 23 districts of them (Table 1a). The highest proportion of districts with a significant decreasing trend (in 12 out of 49 districts) expects in Uttar Pradesh state. Also in the state of Punjab, a significant decreasing trend anticipates in more than half of the districts (in 7 out of 12 districts). Apart from this, a significant decreasing trend in CWR is also likely to happen in four districts, two each in Haryana and West Bengal states. For wheat, the water requirement decreased between 15.3 and $17.4 \mathrm{~mm}$ in $30 \mathrm{yr}$, the highest values are likely to be experience in Punjab. Though statistically insignificant, increasing trend is also projected in 22 districts $(5.6 \%)$, out of which districts are expected in Rajasthan state. When all the significant levels put together, the decrease in CWR is more likely to experience in Punjab (@15.5 mm) and Uttar Pradesh (@9.3 mm)states, that may affect 45.2 per cent of the wheat growing areas of the country. Like CWR, IWR is also expected to decrease under projected future climate change scenarios in 199 districts (90.3\%), among this in 5 districts (four in Maharashtra and one in West Bengal) a significant trend is projected (14.4 - $18.3 \mathrm{~mm}$ in $30 \mathrm{yr}$ ) (Table 1b). In the remaining 28 districts, a non-significant increasing trend was projected, among which 14 districts are anticipated in Rajasthan state, followed by 5 in Punjab and two each in Bihar, Gujarat, Haryana and Jharkhand states.

During climatic period 2051-80 the trend analysis projects an increasing trend in CWR during future climatic period 2051-80 (Table 2a), which is in opposite to the trend that projects in 2021-50. Among 214 districts, that project an increasing trend, 31 districts $(14.4 \%)$ are likely to be statistically significant. Madhya Pradesh leads with 20 districts, followed by Gujarat state with seven districts projects significantly increasing trend. Across these regions, water requirement for wheat is projected to vary between 8.4 to $21.3 \mathrm{~mm}$ in $30 \mathrm{yr}$, with highest requirement in Madhya Pradesh. Only 13 districts (4.6\%) projected a non-significant decreasing trend in CWR, out of which 10 districts are in Rajasthan state. Among the states, the increasing demand of CWR is more likely to appear in Madhya Pradesh (@ 16.5 mm),Gujarat (@10.0mm) and Uttar Pradesh (@9.2 mm), when all the levels of significance are grouped together. Like in the case of CWR, the trend test projected an increasing trend in IWR in 127 districts, out of which six districts (Gujarat) are statistically significant (Table 2b) .

\section{Future trends in crop growing period}

The decreasing crop water requirement trend projected in 2021-50 (Table 1a) and increasing trend projected in 2051-80 (Table 2 a) climatic periods in about 95 per cent of the wheat growing districts of the country are the results that can be explained by change in crop duration, as a result of change in temperature. Being a thermo-sensitive crop, change in air temperature may alter the crop growing period. Less amount of water is needed in a shorter crop growing season and conversely more water are required 
Table 1: Trend analysis of CWR, IWR and crop duration projected for 2021-50 climatic period

\begin{tabular}{|c|c|c|c|c|c|c|c|c|c|}
\hline \multirow[t]{2}{*}{ State } & \multicolumn{4}{|c|}{ Percentage area of districts showing } & \multicolumn{5}{|c|}{ Magnitude of change } \\
\hline & $\uparrow S$ & $\uparrow \mathrm{NS}$ & $\downarrow \mathrm{L}$ & $\downarrow \mathrm{NS}$ & $\uparrow \mathrm{S}$ & $\uparrow \mathrm{NS}$ & $\downarrow S$ & $\downarrow \mathrm{NS}$ & Average \\
\hline \multicolumn{10}{|l|}{ (a) CWR } \\
\hline Bihar & - & $0.3(2)$ & - & $7.0(22)$ & - & 4.5 & - & -6.3 & -5.4 \\
\hline Chhattisgarh & - & - & - & $0.3(7)$ & - & - & - & -6.9 & -6.9 \\
\hline Gujarat & - & $0.8(3)$ & - & $4.1(15)$ & - & 2.7 & - & -3.6 & -2.6 \\
\hline Haryana & - & - & $0.9(2)$ & $6.5(10)$ & - & - & -16.2 & -6 & -7.7 \\
\hline Jharkhand & - & $0(1)$ & - & $0.1(4)$ & - & 2.1 & - & -4.8 & -3.4 \\
\hline Madhya Pradesh & - & $1.2(3)$ & - & $19.2(35)$ & - & 0.9 & - & -6.3 & -5.7 \\
\hline Maharashtra & - & $0.3(2)$ & - & $3.7(20)$ & - & 1.5 & - & -4.5 & -4 \\
\hline Punjab & - & - & $6.0(7)$ & $4.8(5)$ & - & - & -17.4 & -12.9 & -15.5 \\
\hline Rajasthan & - & $2.8(10)$ & - & $6.3(16)$ & - & 6.6 & - & -3.6 & 0.3 \\
\hline Uttar Pradesh & - & - & $8.4(12)$ & $26.0(37)$ & - & - & -16.5 & -6.9 & -9.3 \\
\hline West Bengal & - & $0.2(1)$ & $0.1(2)$ & $1.0(11)$ & - & 2.1 & -15.3 & -4.2 & -5.3 \\
\hline Total & - & $5.6(22)$ & $15.4(23)$ & $79(182)$ & - & 4.2 & -16.6 & -5.8 & -5.9 \\
\hline \multicolumn{10}{|l|}{ (b) IWR } \\
\hline Bihar & - & $0.3(2)$ & - & $7.0(22)$ & - & 3.9 & - & -5.1 & -4.4 \\
\hline Chhattisgarh & - & - & - & $0.3(7)$ & - & - & - & -12 & -12 \\
\hline Gujarat & - & $0.5(2)$ & - & $4.4(16)$ & - & 3.3 & - & -4.5 & -3.6 \\
\hline Haryana & - & $0.9(2)$ & - & $6.5(10)$ & - & 2.1 & - & -5.4 & -4.2 \\
\hline Jharkhand & - & $0(2)$ & - & $0.1(3)$ & - & 1.8 & - & -13.2 & -7.2 \\
\hline Madhya Pradesh & - & - & - & $20.4(38)$ & - & - & - & -13.2 & -13.2 \\
\hline Maharashtra & - & - & $0.8(4)$ & $3.2(18)$ & - & - & -18.3 & -15.6 & -16.1 \\
\hline Punjab & - & $3.8(5)$ & - & $7.0(7)$ & - & 4.2 & - & -12.3 & -5.4 \\
\hline Rajasthan & - & $4(14)$ & - & $5.1(12)$ & - & 5.1 & - & -5.7 & 0.1 \\
\hline Uttar Pradesh & - & - & - & $34.4(49)$ & - & - & - & -7.5 & -7.5 \\
\hline West Bengal & - & $0.2(1)$ & $0.1(1)$ & $1.1(12)$ & - & 1.2 & -14.4 & -15.3 & -14.1 \\
\hline Total & - & $9.7(28)$ & $0.8(5)$ & $89.5(194)$ & - & 4.1 & -17.5 & -9.5 & -8 \\
\hline \multicolumn{10}{|l|}{ (c) Crop duration } \\
\hline Bihar & - & - & $7.0(22)$ & $0.3(2)$ & - & - & -7 & -5 & -7 \\
\hline Chhattisgarh & - & - & $0.3(7)$ & - & - & - & -6 & - & -6 \\
\hline Gujarat & - & - & $4.5(14)$ & $0.4(4)$ & - & - & -6 & -6 & -6 \\
\hline Haryana & - & - & $0.9(2)$ & $6.5(10)$ & - & - & -8 & -6 & -7 \\
\hline Jharkhand & - & - & $0.1(5)$ & - & - & - & -6 & - & -6 \\
\hline Madhya Pradesh & - & - & $2.9(8)$ & $17.5(30)$ & - & - & -6 & -6 & -6 \\
\hline Maharashtra & - & - & $1.2(8)$ & $2.8(14)$ & - & - & -7 & -5 & -6 \\
\hline Punjab & - & - & $10.8(12)$ & - & - & - & -9 & - & -9 \\
\hline Rajasthan & - & - & $1.0(4)$ & $8.1(22)$ & - & - & -6 & -5 & -5 \\
\hline Uttar Pradesh & - & - & $15.4(22)$ & $19(27)$ & - & - & -8 & -6 & -7 \\
\hline West Bengal & - & - & $1.3(14)$ & - & - & - & -6 & - & -6 \\
\hline Total & - & - & $45.4(118)$ & $54.6(109)$ & - & - & -7 & -6 & -6 \\
\hline
\end{tabular}

$\uparrow \boldsymbol{S}$ - Significant increasing trend; $\uparrow N S$ - Non-significant increasing trend; $\downarrow$ S-- Significant decreasing trend; $\downarrow$ NS- Nonsignificant decreasing trend; Figures in the parenthesis represents number of districts 
Table 2: Trend analysis of CWR, IWR and crop duration projected for 2051-80 climatic period

\begin{tabular}{|c|c|c|c|c|c|c|c|c|c|}
\hline \multirow[t]{2}{*}{ State } & \multicolumn{4}{|c|}{ Percentage area of districts showing } & \multicolumn{5}{|c|}{ Magnitude of change } \\
\hline & $\uparrow \mathrm{S}$ & $\uparrow \mathrm{NS}$ & $\downarrow S$ & $\downarrow \mathrm{NS}$ & $\uparrow S$ & $\uparrow \mathrm{NS}$ & $\downarrow S$ & $\downarrow \mathrm{NS}$ & Average \\
\hline \multicolumn{10}{|l|}{ (a) CWR } \\
\hline Bihar & - & $7.3(24)$ & - & - & - & 4.8 & - & - & 4.8 \\
\hline Chhattisgarh & - & $0.3(7)$ & - & - & - & 3.6 & - & - & 3.6 \\
\hline Gujarat & $1.3(7)$ & $3.5(10)$ & - & $0.1(1)$ & 18 & 5.7 & - & -3 & 10 \\
\hline Haryana & - & $6.1(11)$ & - & $1.3(1)$ & - & 8.1 & - & -2.7 & 7.2 \\
\hline Jharkhand & - & $0.1(5)$ & - & - & - & 4.8 & - & - & 4.8 \\
\hline Madhya Pradesh & $12.1(20)$ & $8.3(18)$ & - & - & 21.3 & 11.1 & - & - & 16.5 \\
\hline Maharashtra & $0.2(1)$ & $3.7(21)$ & - & - & 14.4 & 8.1 & - & - & 8.4 \\
\hline Punjab & - & $10.1(11)$ & - & $0.7(1)$ & - & 3 & - & -0.9 & 2.7 \\
\hline Rajasthan & - & $6.6(16)$ & - & $2.5(10)$ & - & 4.8 & - & -1.8 & 2.3 \\
\hline Uttar Pradesh & $0.7(1)$ & $33.6(48)$ & - & - & 18 & 9 & - & - & 9.2 \\
\hline West Bengal & $0.1(2)$ & $1.3(12)$ & - & - & 8.4 & 4.8 & - & - & 5.3 \\
\hline Total & $14.4(31)$ & $81(183)$ & - & $4.6(13)$ & 19.4 & 7 & - & -1.9 & 8.2 \\
\hline \multicolumn{10}{|l|}{ (b) IWR } \\
\hline Bihar & - & $4.2(15)$ & - & $3.1(9)$ & - & 4.2 & - & -6.6 & 0.2 \\
\hline Chhattisgarh & - & $0.1(3)$ & - & $0.2(4)$ & - & 6.9 & - & -2.4 & 1.6 \\
\hline Gujarat & $1.3(6)$ & $2.9(10)$ & - & $0.7(2)$ & 17.4 & 6.3 & - & -2.4 & 9 \\
\hline Haryana & - & $1.3(4)$ & - & $6.1(8)$ & - & 2.7 & - & -9 & -5.1 \\
\hline Jharkhand & - & $0(2)$ & - & $0.1(3)$ & - & 4.5 & - & -6.3 & -2 \\
\hline Madhya Pradesh & - & $16.6(28)$ & - & $3.8(10)$ & - & 9.9 & - & -6 & 5.7 \\
\hline Maharashtra & - & $0.2(2)$ & - & $3.7(20)$ & - & 5.4 & - & -8.4 & -7.1 \\
\hline Punjab & - & - & - & $10.8(12)$ & - & - & - & -17.1 & -17.1 \\
\hline Rajasthan & - & $5.6(13)$ & - & $3.5(13)$ & - & 3 & - & -3.6 & -0.3 \\
\hline Uttar Pradesh & - & $29.4(40)$ & - & $5(9)$ & - & 8.1 & - & -4.5 & 5.8 \\
\hline West Bengal & - & $0.7(4)$ & - & $0.6(10)$ & - & 3.3 & - & -8.4 & -5.1 \\
\hline Total & $1.3(6)$ & $61.1(121)$ & -3 & $7.6(100)$ & 17.4 & 6.9 & - & -7.7 & 0.7 \\
\hline \multicolumn{10}{|l|}{ (a) Crop duration } \\
\hline Bihar & - & $5.4(19)$ & - & $1.9(5)$ & - & 2 & - & -1 & 1 \\
\hline Chhattisgarh & - & $0.3(7)$ & - & - & - & 3 & - & - & 3 \\
\hline Gujarat & $3.2(12)$ & $1.7(6)$ & - & - & 5 & 2 & - & - & 4 \\
\hline Haryana & - & $5.2(9)$ & - & $2.2(3)$ & - & 1 & - & -2 & 1 \\
\hline Jharkhand & - & $0.1(5)$ & - & - & - & 4 & - & - & 4 \\
\hline Madhya Pradesh & $16.7(31)$ & $3.7(7)$ & - & - & 7 & 4 & - & - & 6 \\
\hline Maharashtra & $2.2(13)$ & $1.7(9)$ & - & - & 4 & 2 & - & - & 3 \\
\hline Punjab & - & $1.4(2)$ & - & $9.4(10)$ & - & 1 & - & -2 & -1 \\
\hline Rajasthan & $1.3(4)$ & $6.4(18)$ & - & $1.4(4)$ & 4 & 2 & - & -1 & 2 \\
\hline Uttar Pradesh & $0.7(1)$ & $26.9(38)$ & - & $6.7(10)$ & 6 & 2 & - & -1 & 1 \\
\hline West Bengal & - & $1.2(11)$ & - & $0.2(3)$ & - & 2 & - & -2 & 1 \\
\hline Total & $24.1(61)$ & $54.1(131)$ & - & $21.8(35)$ & 6 & 2 & - & -1 & 3 \\
\hline
\end{tabular}

$\uparrow \boldsymbol{S}$ - Significant increasing trend; $\uparrow \boldsymbol{N S}$ - Non-significant increasing trend; $\downarrow$ S-- Significant decreasing trend; $\downarrow$ NS- Nonsignificant decreasing trend; Figures in the parenthesis represents number of district 
during longer crop duration. The phenological advances across major wheat growing parts of the country have been reported by various researchers. Observational studies of Dhiman et al. (1985) revealed that in wheat; for a $1{ }^{\circ} \mathrm{C}$ rise in air temperature the crop duration was reduced by four days in north India.

A small shift, even in a single growth period will modify wheat crop's stage specific and seasonal water requirements at farm-scale, since water requirement is specific to its phenological stage. A decreasing trend in crop duration was projected across the entire wheat growing districts in 2021-50 climatic period (Table 1c), out of which 118 districts are significant. The crop duration is projected to decrease between 6 to 9 days in $30 \mathrm{yr}$, highest values are expected in Punjab, followed by Haryana and Uttar Pradesh (8 days). Trend in CWR also projects a decreasing trend in 205 districts, out of which 23 districts are statistically significant (Table 1a). The districts that projects significant deceasing trend belongs to Uttar Pradesh (12), Punjab (7), Haryana (2), and West Bengal (2) states, that forms a major part of the IGP. The water requirement is projected to decrease between 15.3 and $17.4 \mathrm{~mm}$ in $30 \mathrm{yr}$, the highest values are observed in Punjab followed by Uttar Pradesh (16.5 mm) and Haryana $(16.2 \mathrm{~mm})$. The decreasing trend of CWR is in agreement with the research findings of Chattaraj et al. (2014) in which probable decline in CWR in wheat by 11 per cent in 202021 and 23 per cent in 2050-51 across the IGP of India was reported. During the second half of $21^{\text {st }}$ century (2051-80), trend in crop duration projected an increase in 192 districts (78.2\%), among which 61 districts are statistically significant (Table 2c). The crop duration is projected to increase between 4 to 7 days in $30 \mathrm{yr}$ period; longer duration anticipates in Madhya Pradesh followed by Uttar Pradesh (6 days). CWR also shows a similar trend in 214 districts (95.4\%) among which 31 districts are statistically significant with highest water requirement projected in Madhya Pradesh $(21.3 \mathrm{~mm})$ followed by Uttar Pradesh and Gujarat with $18 \mathrm{~mm}$ (Table 2a).

Under rising temperature, shifts in growing period seem inevitable which can eventually affects future crop water need. However, the close inspection of trend results indicated that decreasing/increasing trend of CWR across wheat growing districts of the country cannot be attributed to decreasing/increasing trend of crop duration alone. For instance, the significantly decreasing trend of crop duration projects in 118 districts during 2021-50 climatic periods, whereas decreasing trend (statistically significant) of CWR was projected only in 23 districts. Similar the case in 2051 80 climatic period, in which significant increasing trend of crop duration was projected in 61 districts whereas increasing trend of CWR was projected only in 31 districts. This affirms that projected changes in CWR can also be mediated through changes in other weather parameters viz., lower radiation values, smaller diurnal temperature range, higher air humidity, lower wind speed. Present $\mathrm{CO}_{2}$ concentration is nearly $409 \mathrm{ppm}$ (https://www.co2.earth/) which is projected to peak around mid century (with respect to RCP 4.5), then decline rapidly over 30 years and stabilize thereafter (Meinshausen et al., 2011). The increasing concentration of $\mathrm{CO}_{2}$ levels until the mid century may be one among the reason in projecting decreasing trend in CWR during 202150 climatic periods.

\section{CONCLUSION}

Crop and irrigation water requirements were likely to decrease over 94.4 per cent of crop growing areas @ $7.0 \mathrm{~mm}$ and 90.3 percent @9.7 mm during 2021-50 climatic periods. Among the states, decrease in CWR is likely to affect more in Punjab@15.5 mm,whereas IWR is expected to decrease more in Maharashtra state (@16.1 mm). On the other hand, during 2051-80 climatic period water requirement is projected to increase in which CWR is expected to rise more in Madhya Pradesh state (@16.5 mm),followed by Gujarat (@10.0 mm).This shows that, impacts of climate change on water demand are not adverse in relation to agricultural water demand in 2021-50 climatic period, whereas it will enhance the water requirements in 2051-80. The underlying cause of this change with respect to two climatic periods is due to the difference in crop duration, which is expected to decrease 6 to 9 days across entire crop growing area in 202150 , whereas it is likely to increase over 78.2 per cent during 2051-80.

\section{REFERENCES}

Bapuji Rao, B., Sandeep, V.M., Rao, V.U.M. and Rao, A.V.M.S. (2012). Climatic change and crop water requirements: An assessment for future climates. J. Agrometeorol., 14: 125-129.

Chattaraj, S., Chakrabort, D., Sehgal, V.K., Paul, R.K., Singh, S.D., Daripa, A. and Pathak, H. (2014). Predicting the impact of climate change on water requirement of wheat in the semi-arid Indo-Gangetic plains of India. Agric. Ecosyst. Environ., 197: 174-183.

Dhiman, S.D., Singh, D.P. and Sharma, H.C. (1985). Grain 
growth of wheat as influenced by time of sowing and nitrogen fertilisation. Har. Agric. Uni. J. Res., 15: 158163.

Garg,A., Mishra Vimal. and Dholakia,H. (2015). Climate change and India: adaptation gap (2015) - A Preliminary Assessment. Working paper of Indian Institute of Management Ahmedabad (IIMA) W.P. No. 2015-11-01.

IPCC (Intergovernmental Panel on Climate Change). (1995). "Climate Change 1995: IPCC Second Assessment Report”. IPCC,Cambridge University Press, Cambridge.

Liu, C.Z. (2002). Suggestion on water resources in China corresponding with global climate change. China Water Resour., 2: 36-37.

Meinshausen, M., Smith, S.J., Calvin, K., Daniel, J.S., Kainuma, M.L.T., Lamarque, J-F., Matsumoto, K., Montzka, S.A., Raper, S.C.B., Riahi, K., Thomson, A., Velders, G.J.M. and van Vuuren, D.P.P. (2011). The RCP greenhouse gas concentrations and their extensions from 1765 to 2300 . Clim. Change, 109: 213-241.
Nuttonson, M.Y.(1955). "Wheat Climate Relationships and the Use of Phenology in Ascerting the Thermal and Photo Thermal Requirements of Wheat". ${ }^{\text {st }}$ Eds. (American Institute of Crop Ecology, Washington). pp. 388.

Parekh, F. and Prajapati, K.P. (2013). Climate change impacts on crop water requirement for Sukhi reservoir project. Int. J. Innov. Res. Sci. Eng. Tech., 2 (9): 4685-4692.

Pragyan Kumari., Wadood, A., Singh, R.B. and Ramesh Kumar. (2009). Response of wheat crop to different thermal regimes under the agroclimatic conditions of Jharkhand. J. Agrometeorol. 11 (1): 85-88.

Sandeep, V.M., Bapuji Rao, B., Bharathi, G., Rao, V.U.M., Pramod, V.P., Santhibhushan Chowdary, P., Patel, N.R. and Vijayakumar,P. (2017). Projecting future changes in water requirement of grain sorghum in India. $J$. Agrometeorol., 19 (3): 217-225.

Shiklomanov,A. and Rodda, J.C.(2003). "WorldWater Resources at the Beginning of the $21^{\text {st }}$ Century". (Cambridge University Press, New York). pp. 435. 